\title{
THE IMPACT OF THE COVID-19 ON THE FINANCIAL MARKETS: EVIDENCE FROM G7
}

\author{
Paula Heliodoro ${ }^{1}$ \\ Rui Dias ${ }^{2}$ \\ Paulo Alexandre ${ }^{3}$ \\ Maria Manuel ${ }^{4}$
}

DOI: https://doi.org/10.31410/ITEMA.2020.103

\begin{abstract}
This essay aims to analyse the impact of the 2020 global pandemic on the stock indexes of France (CAC 40), Germany (DAX 30), USA (DOW JONES), United Kingdom (FTSE 100), Italy (FTSE MID), Japan (Nikkei 225) and Canada (TSX 300), from January 2018 to June 2020, with the sample being divided into two sub periods: first sub period from January 2018 to August 2019 (Pre-Covid); second period from September 2019 to June 2020 (Covid19). In order to carry out this analysis, different approaches were taken in order to analyse whether: (i) the global pandemic (Covid-19) increased the persistence of the G7 financial markets? In the Pre-Covid period, we can verify the presence of long memories in the Canadian market (TSX), while the markets in France (CAC 40) and Italy (FTSE MID) show signs of balance, since the random walk hypothesis was not rejected. The German (DAX 30), USA (DJI), United Kingdom (FTSE 100) and Japan (NIKKEI 225) markets have antipersistence $(0<\alpha<0.5)$. In period II, the Covid-19-time scale is contained, and we verified the presence of significant long memories, except for the US stock index (0.49). These findings make it possible to show that the assumption of the market efficiency hypothesis may be called into question, because these markets are predictable, which validate the research question. The results of the pDCCA correlation coefficients, in the Pre-Covid period, show 14 pairs of median markets $(0.333 \rightarrow \cong 0.666)$. We can also see 7 pairs of markets with strong correlation coefficients $(0.666 \rightarrow \cong 1,000)$, showing that these markets have a tendency towards integration, this evidence may call into question the hypothesis of portfolio diversification. In period II (Covid-19) the $\lambda$ _DCCA correlation coefficients have 7 strong market pairs (0.666 $\rightarrow \cong 1,000)$, 5 pairs have weak $p D C C A$ coefficient $(0.000 \rightarrow \cong 0.333), 5$ market pairs show anti-correlation $(-1.000 \rightarrow \cong 0.000)$, and 4 market pairs show median coefficients ( $p D C C A)$ $(0.333 \rightarrow \cong 0.666)$ (out of 21 possible). When compared to the previous subperiod, we found that the majority of the pDCCAs decreased, which shows that the markets have decreased their integration, making it possible to diversify portfolios in certain markets, especially in the Japanese market (NIKKEI 225). These conclusions open space for market regulators to take measures to ensure better informational information, in the stock markets, in the 7 most advanced economies in the world.
\end{abstract}

Keywords: Covid-19, G7, Persistence, Long memories, Arbitration.

Escola Superior de Ciências Empresarias, Instituto Politécnico de Setúbal, Portugal Escola Superior de Ciências Empresarias, Instituto Politécnico de Setúbal, Portugal \& CEFAGE, Universidade de Évora, Portugal

Escola Superior de Ciências Empresarias, Instituto Politécnico de Setúbal, Portugal

Escola Superior de Ciências Empresarias - Instituto Politécnico de Setúbal, Portugal 


\section{INTRODUCTION}

The efficient market hypothesis (HME) argues that bond prices reflect all available information and that investors cannot obtain anomalous returns by trading based on this information (Fama, 1970). HME is an essential concept for financial institutions, individual and institutional investors, and government regulators. An investor's investment strategy is greatly influenced by market efficiency. Market efficiency also determines the regulatory measures to be developed to ensure the development and organized management of a country's markets (Dsouza and Mallikarjunappa, 2015; Shirvani and Delcoure, 2016).

The huge amount of data caught the attention of the audience of academics. Statistical physicists began to analyse financial data, creating an interdisciplinary research area called Econophysics (Gallegati, 2016; Pereira, da Silva and Pereira, 2017).

In this work, we will test the persistence of the profitability of the G7 financial markets, having the sample been divided into two sub-periods: Pre-Covid and Covid. To answer the research question, we will use the DFA methodology and the DCCA cross-correlation coefficient, to analyse the dependency pattern between the various indices under analysis. First, the objective is to assess the degree of efficiency of these indices; the individual analysis can provide information on the profitability of this type of investment. As we will use a sliding window approach, we can also assess how this efficiency has evolved over time. Second, with the $p D C C A$, we want to assess how these markets relate to each other. This can be important, as it can analyse the correlation between the indices and reveal the existence (or not) of connections between the markets, which could also be important for existing and potential investors. The results suggest that the global pandemic (Covid-19) has increased the persistence of profitability in the G7 financial markets, which could jeopardize efficiency, in its weak form. Additionally, we verified that the $p D C C A$ correlation coefficients decreased in this period of the pandemic, that is, the level of integration has slowed down, making it possible to diversify portfolios in certain markets, mainly in the Japan market (NIKKEI 225).

This investigation adds contributions to the literature, specifically testing the fractal analysis in the G7 markets, that is, assessing the presence of long memories, in the context of the pandemic of the COVID-19 outbreak. As far as we know, this is the first study to analyse these financial markets in isolation. However, there are recent studies that have analysed the diversification of risk and the impact of the global pandemic, namely the authors Liu, Manzoor, Wang, Zhang and Manzoor (2020), Zeren and Hizarci (2020). However, the approach was quite different from that followed in this essay.

In terms of structure, this essay is organized in 5 sections. Section 2 presents a literature review on the hypothesis of an efficient market in international financial markets. Section 3 describes the methodology and data. Section 4 contains the results. Section 5 concludes.

\section{LITERATURE REVISION}

Different studies have addressed the issue of market efficiency, analysing the hypothesis of predictability of returns, through the analysis of patterns of reversion to the average of stock prices, inspired by the seminal works of Poterba and Summers (1988), Fama and French (1988), who documented the reversal to the average in the returns of the stock markets, over time horizons of more than one year. 
This theme has motivated other studies to analyse the implications in the hypothesis of efficiency of the markets, according to which the current price of the assets reflects all the available information, in a given moment, and the price adjusts quickly, as new and unforeseen information is reaching the market. The mean reversion hypothesis, also known as negative series correlation, has been interpreted as an efficient correction mechanism in developed markets and a sign of a speculative bubble in emerging financial markets (Lawrence $\mathrm{H}$. Summers, 1986; Fama and French, 1988)

Ayentimi, Mensah, and Naa-Idar (2013), Dourado and Tabak (2014), Robinson (2016), Ngene, Tah, and Darrat (2017 tested the random walk hypothesis in the stock markets. Ayentimi, Mensah, and Naa-Idar (2013) examined the efficiency of companies listed on the Ghana Stock Exchange (GSE). The authors suggest that the market is inefficient and recommend that transaction costs be reduced in order to improve market activities (GSE). Dourado and Tabak (2014) evaluated the efficiency of the São Paulo stock exchange, from January 1995 to December 2012. The authors show that the RWH hypothesis cannot be rejected, showing signs of efficiency. Robinson (2016) investigated the Jamaica Stock Exchange (JSE), evidencing that the random walk hypothesis was rejected. Ngene, Tah, and Darrat (2017) examined 18 emerging markets in the presence of multiple, unforeseen and successive structural breaks. Random walk hypothesis is rejected. However, when using double-level change tests on the average and due tolerance to various structural breaks is made, the results are consistent with the random walk hypothesis in most markets.

Hamid, Suleman, Ali Shah and Imdad Akash (2017), Awan and Subayyal (2018), Fernando and Gunasekara (2018), Chaker and Sabah (2018) tested market efficiency, in its weak form, in the stock markets. Hamid, Suleman, Ali Shah and Imdad Akash (2017) show that the financial markets of Pakistan, India, Sri Lanka, China, Korea, Hong Kong, Indonesia, Malaysia, Philippines, Singapore, Thailand, Taiwan, Japan and Australia, do not follow the random walk hypothesis. Awan and Subayyal (2018) analysed the stock exchanges of Oman, United Arab Emirates, Kuwait, Saudi Arabia, Bahrain and Qatar, and show that these markets show signs of (in) efficiency, in their weak form. Fernando and Gunasekara (2018) show that the ASPI index (All Share Price Index) of the CSE market, shows signs of (in) efficiency, in its weak form, although the market efficiency is mostly dynamic. Chaker and Sabah (2018) tested efficiency in the GCCC, United Arab Emirates, Saudi Arabia, Oman, Kuwait and Bahrain markets, except in Qatar. The results suggest that none of the five stock markets follow the random walk hypothesis.

Mphoeng (2019), Pernagallo and Torrisi (2019), Malafeyev, Awasthi, S. Kambekar, and Kupinskaya (2019), tested efficiency, in its weak form, and tested whether markets are predictable. Mphoeng (2019) tested the efficient market hypothesis in the Botswana stock market, showing that the random walk hypothesis was rejected, which maintains that the market is inefficient in the analysed period. Pernagallo and Torrisi (2019) analysed whether the behaviour of the daily returns of the stock market indexes of 12 emerging economies corroborates the hypothesis of "fat tails" and whether these series show long memory. Hurst's exponents range from 0.51 to 0.62 showing significant long memories. Malafeyev, Awasthi, S. Kambekar, and Kupinskaya (2019) show that the stock markets of China and India do not show efficiency, in their weak form, in the first three periods (1996 to 2015).

Tebyaniyan, Jahanshad, and Heidarpoor (2020), Karasiński (2020), Aslam, Mohti, and Ferreira (2020) tested the presence of long-term memories in the financial markets. Tebyaniyan, Jahanshad, and Heidarpoor (2020) analysed the share prices of companies on the Tehran stock 
exchange. The test results indicate that stock prices have a multifractal property, and have long memories, which implies market inefficiency, in its weak form. Karasiński (2020) examined the efficiency of European stock markets; the results show a partial rejection of the random walk hypothesis, noting that, in the long run, the efficiency of European stock markets tends to improve in the post-2008 financial crisis. Aslam, Mohti, and Ferreira (2020) assessed how the coronavirus pandemic (Covid-19) affects the memory properties of 8 European stock exchanges, with five-minute data. The authors show that the Spanish stock market remains the most efficient, while the least efficient is that of Austria. The Belgium, Italy and Germany markets show 0.5 results.

\section{METHODOLOGY}

\section{DATA}

Closing price data on the stock indices of France (CAC 40), Germany (DAX 30), USA (DOW JONES), United Kingdom (FTSE 100), Italy (FTSE MID), Japan (Nikkei 225) and Canada (TSX 300), were obtained from the Thomson Reuters platform. The quotations are daily and cover the period from January 3, 2018 to June 1, 2020, with the sample being divided into two sub periods: first sub period from January 2018 to August 2019 (Pre-Covid); second period from September 2019 to June 2020 (Covid-19). Quotations are in local currency, to mitigate exchange rate distortions.

Table 1. The name of countries and their indices used in this paper

\begin{tabular}{|l|c|}
\hline \multicolumn{1}{|c|}{ Country } & Index \\
\hline France & CAC 40 \\
\hline Germany & DAX 30 \\
\hline USA & DOW JONES \\
\hline United Kingdom & FTSE 100 \\
\hline Italy & FTSE MID \\
\hline Japan & NIKKEI 225 \\
\hline Canada & TSX 300 \\
\hline
\end{tabular}

Source: Own elaboration

\section{METHODOLOGY}

The development of the research took place over several stages. In order to answer the research question, we will use the methodology Detrended Fluctuation Analysis (DFA), and Detrended Cross-Correlation Analysis $(p D C C A)$. DFA is an analysis method that examines time dependency on non-stationary data series. This technique, assuming that the time series are non-stationary, avoids spurious results when the analysis focuses on the relationships of the data series in the long run. The DFA has the following interpretation: $0<\alpha<0.5$ : anti-persistent series; $\alpha=0.5$ series has a random walk; $0.5<\alpha<1$ persistent series. The function of this technique is to examine the relationship between the $\mathrm{x}_{-} \mathrm{k}$ and $\mathrm{x}_{-}(\mathrm{k}+\mathrm{t})$ values at different times (Guedes et al., 2018). Zebende's (2011) trendless cross correlation coefficient ( $p D C C A$ ) is a method for quantifying the level of cross correlation between two non-stationary time series. The coefficient is based on the DFA (Peng et al., 1994) and DCCA (Podobnik and Stanley, 2008) methods. The cross-correlation coefficient depends on the length of the box s (time scale). One of the advantages of this cross-correlation coefficient is centred on the possibility of measuring the correlations between two non-stationary time series at different time scales. The function of this technique is to examine the relationship between the $x_{-} k$ and $x_{-}(k+t)$ 
values at different times (Ferreira, Dionísio, Guedes and Zebende, 2018). Tables 2 and 3 show the interpretation of the exponents $\alpha \_$DFA and $p D C C A$.

Table 2. Detrended Fluctuation Analysis $\alpha_{\text {DFA }}$

\begin{tabular}{|c|c|}
\hline Exponent & Type of signal \\
\hline$\alpha_{\mathrm{DFA}}<0.5$ & long-range anti-persistent \\
\hline$\alpha_{\mathrm{DFA}} \simeq 0.5$ & uncorrelated, white noise \\
\hline$\alpha_{\mathrm{DFA}}>0.5$ & long-range persistent \\
\hline
\end{tabular}

Source: Own elaboration

Table 3. Detrended cross-correlation coefficient, $p D C C A$, levels

\begin{tabular}{|c|c|c|}
\hline Weak & Medium & Strong \\
\hline$\cong 0.000 \rightarrow \cong 0.333$ & $\cong 0.333 \rightarrow \cong 0.666$ & $\cong 0.666 \rightarrow \cong 1.000$ \\
\hline
\end{tabular}

Source: Own elaboration

\section{RESULTS}

Figure 1 shows the evolution of the markets, in terms of profitability, of the G7. The sample comprises the time lapse from January 2018 to June 2020, being a period of considerable complexity, due to understanding the outbreak of the global pandemic (COVID-19). Yields clearly reveal volatility in February, March and April 2020.

Figure 1. Evolution, in profitability, of the G7 financial markets, in the period of 03/01/2018 to $01 / 06 / 2020$

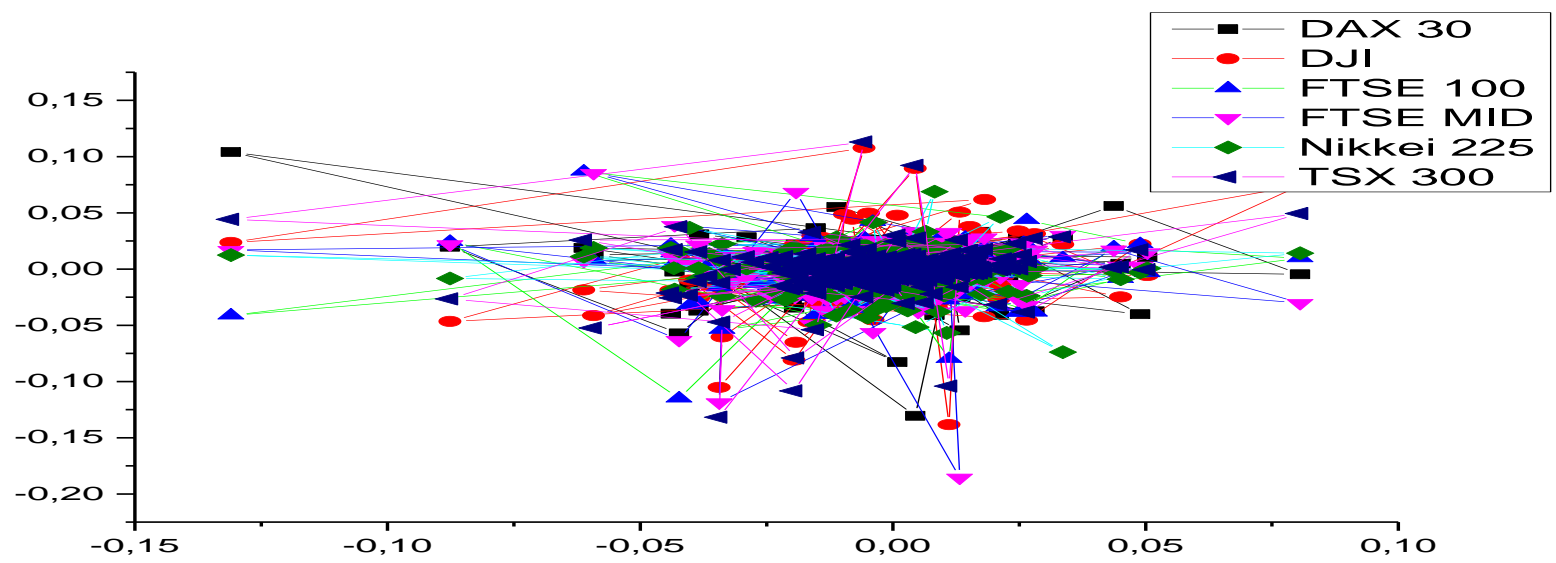

Source: Own elaboration

Table 4 shows the main descriptive statistics for the G7 financial markets. The analysis of descriptive statistics allows us to ascertain that profitability shows negative daily averages, except for the US market (DJI). Asymmetries are negative in the 7 markets, especially in the Italian market (FTSE MID). Short-circuits are above 3, which shows signs of deviation from the hypothesis of normality, with a greater incidence in Italy (FTSE MID). Additionally, the asymmetry and kurtosis coefficients are statistically different from those of a normal distribution. 
Table 4. Descriptive statistics on returns, of the G7 financial markets, in the period of $03 / 01 / 2018$ to $01 / 06 / 2020$

\begin{tabular}{|c|c|c|c|c|c|c|c|}
\hline Index & $\mathrm{N}$ & Mean & $\begin{array}{c}\text { Standard } \\
\text { Deviation }\end{array}$ & Skewness & Kurtosis & Minimum & Maximum \\
\hline CAC 40 & 615 & $-1.78 \mathrm{E}-04$ & 0.01368 & -1.92015 & 19.68111 & -0.13098 & 0.08056 \\
\hline DAX 30 & 615 & $-1.92 \mathrm{E}-04$ & 0.01416 & -1.21737 & 18.98176 & -0.13055 & 0.10414 \\
\hline DJI & 615 & $8.36 \mathrm{E}-06$ & 0.01623 & -0.95021 & 18.16517 & -0.13842 & 0.10764 \\
\hline FTSE 100 & 615 & $-3.59 \mathrm{E}-04$ & 0.01232 & -1.56484 & 19.83532 & -0.11512 & 0.08667 \\
\hline FTSE MID & 615 & $-2.92 \mathrm{E}-04$ & 0.0158 & -3.22624 & 37.12553 & -0.18541 & 0.08549 \\
\hline $\begin{array}{c}\text { NIKKEI } \\
\text { 225 }\end{array}$ & 615 & $-3.39 \mathrm{E}-04$ & 0.01179 & -0.62377 & 6.87018 & -0.07391 & 0.06879 \\
\hline TSX 300 & 615 & $-1.12 \mathrm{E}-04$ & 0.01374 & -1.96528 & 37.4476 & -0.13176 & 0.11294 \\
\hline
\end{tabular}

Source: Own elaboration

Table 5 shows the DFA exponents referring to the stock market indices of the G7 markets. The period I comprises the Pre-Covid time scale and we can verify the presence of long memories in the Canada market (TSX), while the markets in France (CAC 40), and Italy (FTSE MID) show signs of balance, since the random walk hypothesis was not rejected. The German (DAX 30), USA (DJI), United Kingdom (FTSE 100) and Japan (NIKKEI 225) markets have antipersistence $(0<\alpha<0.5)$. In period II, the Covid-19-time scale is contained, and we verified the presence of significant long memories, except for the US stock index (0.49). These findings make it possible to show that the assumption of the market efficiency hypothesis may be called into question, since the forecast of market movement can be improved if the lagged movements of the other markets are considered, allowing arbitrage operations to occur. These results are in line with the findings of the authors Tebyaniyan, Jahanshad, and Heidarpoor (2020), Karasiński (2020), Aslam, Mohti, and Ferreira (2020).

Table 5. DFA exponent for index and return. The values of the linear adjustments for $\alpha$ DFA always had R2 > 0.99 .

\begin{tabular}{|c|c|c|}
\hline Stock market & DFA exponent (before crisis) & DFA exponent (crisis period) \\
\hline CAC 40 & $0.50 \cong 0,0009$ & $0.64 \cong 0.0031$ \\
\hline DAX 30 & $0.47 \cong 0.0036$ & $0.64 \cong 0.0041$ \\
\hline DJI & $0.46 \cong 0.0016$ & $0.49 \cong 0.0054$ \\
\hline FTSE 100 & $0.47 \cong 0.0010$ & $0.55 \cong 0.0064$ \\
\hline FTSE MID & $0.52 \cong 0.0340$ & $0.66 \cong 0.0088$ \\
\hline NIKKEI 225 & $0.49 \cong 0.0033$ & $0.64 \cong 0.0031$ \\
\hline TSX 300 & $0.56 \cong 0.0012$ & $0.54 \cong 0.0272$ \\
\hline
\end{tabular}

Source: Own elaboration.

Note: The hypotheses are $H_{0}: \alpha=0.5$ and $H_{1}: \alpha \neq 0.5$.

Table 6 shows the Detrended cross-correlation coefficient pDCCA for the period from 02 January 2018 to 30 August 2019 (Pre-Covid-19). The G7 financial markets have 14 median cross-correlation coefficients without trend ( $\lambda \_$DCCA) median $(0.333 \rightarrow \cong 0.666$ ) (out of 21 possible). We can also see 7 pairs of markets showing strong correlation coefficients $(0.666$ $\rightarrow \cong 1,000$ ). These findings show that these markets have marked levels of integration, which may jeopardize efficient portfolio diversification. 
Table 6. Summary table of the pDCCA coefficients peaks, in the G7 financial markets, in the sub period 01/02/2018 to 08/30/2019 (Pre-Covid-19)

\begin{tabular}{|l|r|c|c|}
\hline \multicolumn{1}{|c|}{ Index } & \multicolumn{1}{c|}{$\lambda_{\text {DCCA }}$} & Time scale (days) & Trend \\
\hline CAC 40 - DAX 30 & 0.75 & $\mathrm{n}>92$ days & Strong correlation \\
\hline CAC 40 - DJI & $\mathbf{0 . 5 8}$ & $\mathrm{n}>92$ days & Mean correlation \\
\hline CAC 40 - FTSE 100 & 0.71 & $\mathrm{n}>63$ days & Strong correlation \\
\hline CAC 40 - FTSE MID & 0.68 & $\mathrm{n}>76$ days & Strong correlation \\
\hline CAC 40 - NIKKEI 225 & $\mathbf{0 . 4 1}$ & $\mathrm{n}>92$ days & Mean correlation \\
\hline CAC 40 - TSX 300 & $\mathbf{0 . 5 6}$ & $\mathrm{n}>76$ days & Mean correlation \\
\hline DAX 30 - DJI & 0.65 & $\mathrm{n}>76$ days & Mean correlation \\
\hline DAX 30 - FTSE 100 & 0.77 & $\mathrm{n}>76$ days & Strong correlation \\
\hline DAX 30 - FTSE MID & $\mathbf{0 . 6 6}$ & $\mathrm{n}>63$ days & Mean correlation \\
\hline DAX 30 - NIKKEI 225 & $\mathbf{0 . 4 2}$ & $\mathrm{n}>92$ days & Mean correlation \\
\hline DAX 30 - TSX & 0.68 & $\mathrm{n}>76$ days & Strong correlation \\
\hline DJI - FTSE 100 & $\mathbf{0 . 5 8}$ & $\mathrm{n}>76$ days & Mean correlation \\
\hline DJI - FTSE MID & $\mathbf{0 . 4 6}$ & $\mathrm{n}>63$ days & Mean correlation \\
\hline DJI - NIKKEI 225 & $\mathbf{0 . 5 1}$ & $\mathrm{n}>92$ days & Mean correlation \\
\hline DJI - TSX 300 & 0.77 & $\mathrm{n}>92$ days & Strong correlation \\
\hline FTSE 100 - FTSE MID & $\mathbf{0 . 5 9}$ & $\mathrm{n}>63$ days & Mean correlation \\
\hline FTSE 100 - NIKKEI 225 & $\mathbf{0 . 4 4}$ & $\mathrm{n}>92$ days & Mean correlation \\
\hline FTSE 100 - TSX & 0.67 & $\mathrm{n}>92$ days & Strong correlation \\
\hline FTSE MID - NIKKEI 225 & $\mathbf{0 . 3 6}$ & $\mathrm{n}>76$ days & Mean correlation \\
\hline FTSE MID - TSX 300 & $\mathbf{0 . 5 2}$ & $\mathrm{n}>43$ days & Mean correlation \\
\hline NIKKEI 225 - TSX 300 & $\mathbf{0 . 4 9}$ & $\mathrm{n}>92$ days & Mean correlation \\
\hline
\end{tabular}

Source: Own elaboration

Table 7 shows the Detrended cross-correlation coefficient pDCCA for the period from September 2, 2019 to June 1, 2020 (Covid-19). The G7 financial markets have 7 pairs of strong markets $(0.666 \rightarrow \cong 1,000), 5$ pairs have a weak coefficient pDCCA $(0.000 \rightarrow \cong 0.333), 5$ pairs of markets show anti-correlation $(-1000 \rightarrow 0000.000)$, and 4 pairs of markets show median ( $\lambda \_$DCCA) coefficients $(0.333 \rightarrow \cong 0.666)$ (out of 21 possible). When compared to the previous subperiod, we find that the pDCCAs have mostly decreased, which shows that the markets have decreased their integration, making it possible to diversify portfolios in certain markets, namely in the Japanese market (NIKKEI 225).

Table 7. Summary table of pDCCA coefficients peaks, in the G7 financial markets, in the subperiod 02/09/2019 to 01/06/2020 (Covid-19)

\begin{tabular}{|l|r|c|c|}
\hline \multicolumn{1}{|c|}{ Index } & \multicolumn{1}{c|}{$\lambda_{\text {DCCA }}$} & Time scale (days) & Trend \\
\hline CAC 40 - DAX 30 & $\mathbf{0 . 1 8}$ & $\mathrm{n}>43$ days & Weak correlation \\
\hline CAC 40 - DJI & $\mathbf{0 . 2 4}$ & $\mathrm{n}>43$ days & Weak correlation \\
\hline CAC 40 - FTSE 100 & 0.58 & $\mathrm{n}>43$ days & Mean correlation \\
\hline CAC 40 - FTSE MID & $\mathbf{0 . 3 1}$ & $\mathrm{n}>43$ days & Weak correlation \\
\hline CAC 40 - NIKKEI 225 & $\mathbf{0 . 0 7}$ & $\mathrm{n}>29$ days & Weak correlation \\
\hline CAC 40 - TSX 300 & $\mathbf{0 . 3 1}$ & $\mathrm{n}>43$ days & Weak correlation \\
\hline DAX 30 - DJI & 0.86 & $\mathrm{n}>43$ days & Strong correlation \\
\hline DAX 30 - FTSE 100 & 0.59 & $\mathrm{n}>43$ days & Mean correlation \\
\hline
\end{tabular}




\begin{tabular}{|l|r|c|c|}
\hline DAX 30 - FTSE MID & 0.85 & $\mathrm{n}>43$ days & Strong correlation \\
\hline DAX 30 - NIKKEI 225 & $\mathbf{- 0 . 3 3}$ & $\mathrm{n}>43$ days & Anti correlation \\
\hline DAX 30 - TSX 300 & 0.88 & $\mathrm{n}>43$ days & Strong correlation \\
\hline DJI - FTSE 100 & 0.57 & $\mathrm{n}>43$ days & Mean correlation \\
\hline DJI - FTSE MID & 0.77 & $\mathrm{n}>43$ days & Strong correlation \\
\hline DJI - NIKKEI 225 & $\mathbf{- 0 . 3 1}$ & $\mathrm{n}>43$ days & Anti correlation \\
\hline DJI - TSX 300 & 0.93 & $\mathrm{n}>29$ days & Strong correlation \\
\hline FTSE 100 - FTSE MID & 0.67 & $\mathrm{n}>43$ days & Strong correlation \\
\hline FTSE 100 - NIKKEI 225 & $\mathbf{- 0 . 1 3}$ & $\mathrm{n}>43$ days & Anti correlation \\
\hline FTSE 100 - TSX 300 & 0.62 & $\mathrm{n}>43$ days & Mean correlation \\
\hline FTSE MID - NIKKEI 225 & $\mathbf{- 0 . 2 4}$ & $\mathrm{n}>29$ days & Anti correlation \\
\hline FTSE MID - TSX 300 & 0.77 & $\mathrm{n}>35$ days & Strong correlation \\
\hline NIKKEI 225 - TSX 300 & $\mathbf{- 0 . 2 0}$ & $\mathrm{n}>24$ days & Anti correlation \\
\hline
\end{tabular}

\section{CONCLUSION}

The general conclusion to be retained and sustained by the results obtained, through tests carried out with econophysical models, show that the global pandemic has a significant impact on the adjustment of the analysed financial markets. The results indicate that the G7 markets show significant persistence during the Covid period, which causes some arbitrage opportunities. Additionally, Detrended cross-correlation coefficient pDCCA decreased in the Covid period when compared to the previous subperiod, which improves the possibilities for portfolio diversification. These conclusions also open space for market regulators to take measures to ensure better informational information among international financial markets. In conclusion, we believe that investors should diversify their portfolios, and invest in less risky markets, in order to mitigate risk and improve the efficiency of their portfolios.

\section{REFERENCES}

Aslam, F., Mohti, W., \& Ferreira, P. (2020). Evidence of Intraday Multifractality in European Stock Markets during the Recent Coronavirus (COVID-19) Outbreak. International Journal of Financial Studies. https://doi.org/10.3390/ijfs8020031

Awan, U., \& Subayyal, M. (2018). Weak Form Efficient Market Hypothesis Study: Evidence from Gulf Stock Markets. SSRN Electronic Journal. https://doi.org/10.2139/ssrn.2787816

Ayentimi, D., Mensah, A., \& Naa-Idar, F. (2013). Stock market efficiency of Ghana stock exchange: An objective analysis. International Journal of Management, Economics and Social Sciences (IJMESS).

Chaker, M. N., \& Sabah, A. (2018). Testing the weak form of efficiency of the stock markets in Gulf Cooperation Council countries. Journal for Global Business Advancement. https://doi.org/10.1504/JGBA.2018.096334

Dourado, G. de A., \& Tabak, B. M. (2014). Testing the adaptive markets hypothesis for Brazil. Brazilian Review of Finance.

Dsouza, J. J., \& Mallikarjunappa, T. (2015). Does the Indian Stock Market Exhibit Random Walk? Paradigm. https://doi.org/10.1177/0971890715585197

Fama, E. F. (1970). Efficient Capital Markets: A Review of Theory and Empirical Work. The Journal of Finance. https://doi.org/10.2307/2325486

Fama, E. F., \& French, K. R. (1988). Dividend yields and expected stock returns. Journal of 
Financial Economics. https://doi.org/10.1016/0304-405X(88)90020-7

Fernando, P. N. D., \& Gunasekara, A. L. (2018). Is the Market Efficiency Static or Dynamic Evidence from Colombo Stock Exchange (CSE). Kelaniya Journal of Management. https://doi.org/10.4038/kjm.v7i1.7551

Ferreira, P., Dionísio, A., Guedes, E. F., \& Zebende, G. F. (2018). A sliding windows approach to analyse the evolution of bank shares in the European Union. Physica A: Statistical Mechanics and Its Applications, 490, 1355-1367. https://doi.org/10.1016/j.physa.2017.08.095

Gallegati, M. (2016). Beyond econophysics (not to mention mainstream economics). European Physical Journal: Special Topics. https://doi.org/10.1140/epjst/e2016-60105-6

Guedes, E. F., Brito, A. A., Oliveira Filho, F. M., Fernandez, B. F., de Castro, A. P. N., da Silva Filho, A. M., \& Zebende, G. F. (2018). Statistical test for $\Delta \rho D C C A$ : Methods and data. Data in Brief. https://doi.org/10.1016/j.dib.2018.03.080

Hamid, K., Suleman, M. T., Ali Shah, S. Z., \& Imdad Akash, R. S. (2017). Testing the Weak Form of Efficient Market Hypothesis: Empirical Evidence from Asia-Pacific Markets. SSRN Electronic Journal. https://doi.org/10.2139/ssrn.2912908

Karasiński, J. (2020). The Changing Efficiency of the European Stock Markets. Annales Universitatis Mariae Curie-Skłodowska, Sectio $H_{-}$Oeconomia. https://doi.org/10.17951/h.2020.54.1.41-51

Lawrence H. Summers. (1986). Does the stock market rationally reflect fundamental values. The Journal of Finance. https://doi.org/10.2307/2328487

Liu, H., Manzoor, A., Wang, C., Zhang, L., \& Manzoor, Z. (2020). The COVID-19 outbreak and affected countries stock markets response. International Journal of Environmental Research and Public Health. https://doi.org/10.3390/ijerph17082800

Malafeyev, O., Awasthi, A., S.Kambekar, K., \& Kupinskaya, A. (2019). Random Walks and Market Efficiency in Chinese and Indian Equity Markets. Statistics, Optimization \& Information Computing. https://doi.org/10.19139/soic.v7i1.499

Mphoeng, M. (2019). Testing for Weak-Form Market Efficiency in the Botswana Stock Market. Archives of Business Research. https://doi.org/10.14738/abr.79.6640

Ngene, G., Tah, K. A., \& Darrat, A. F. (2017). The random-walk hypothesis revisited: new evidence on multiple structural breaks in emerging markets. Macroeconomics and Finance in Emerging Market Economies. https://doi.org/10.1080/17520843.2016.1210189

Peng, C. K., Buldyrev, S. V., Havlin, S., Simons, M., Stanley, H. E., \& Goldberger, A. L. (1994). Mosaic organization of DNA nucleotides. Physical Review E, 49(2), 1685-1689. https://doi.org/10.1103/PhysRevE.49.1685

Pernagallo, G., \& Torrisi, B. (2019). An empirical analysis on the degree of Gaussianity and long memory of financial returns in emerging economies. Physica A: Statistical Mechanics and Its Applications. https://doi.org/10.1016/j.physa.2019.121296

Podobnik, B., \& Stanley, H. E. (2008). Detrended cross-correlation analysis: A new method for analyzing two nonstationary time series. Physical Review Letters, 100(8). https://doi.org/10.1103/PhysRevLett.100.084102

Poterba, J. M., \& Summers, L. H. (1988). Mean reversion in stock prices. Evidence and Implications. Journal of Financial Economics. https://doi.org/10.1016/0304405X(88)90021-9

Robinson, C. J. (2016). Stock Price Behaviour in Emerging Markets: Tests for Weak-Form Efficiency on the Jamaica Stock Exchange. SSRN Electronic Journal. https://doi.org/10.2139/ssrn.2845446

Tebyaniyan, H., Jahanshad, A., \& Heidarpoor, F. (2020). Analysis of weak performance hypothesis, multi-fractality feature and long-term memory of stock price in Tehran stock 
exchange. International Journal of Nonlinear Analysis and Applications. https://doi.org/10.22075/ijnaa.2020.4412

Zebende, G. F. (2011). DCCA cross-correlation coefficient: Quantifying level of crosscorrelation. Physica A: Statistical Mechanics and Its Applications, 390(4), 614-618. https://doi.org/10.1016/j.physa.2010.10.022

Zeren, F., \& Hizarci, A. (2020). The impact of Covid-19 coronavirus on stock markets: evidence from selected countries. Muhasebe ve Finans Incelemeleri Dergisi. https://doi.org/10.32951/mufider.706159 